\title{
Studies on effect of alkali pretreatment of banana pseudostem for fermentable sugar production for biobutanol production
}

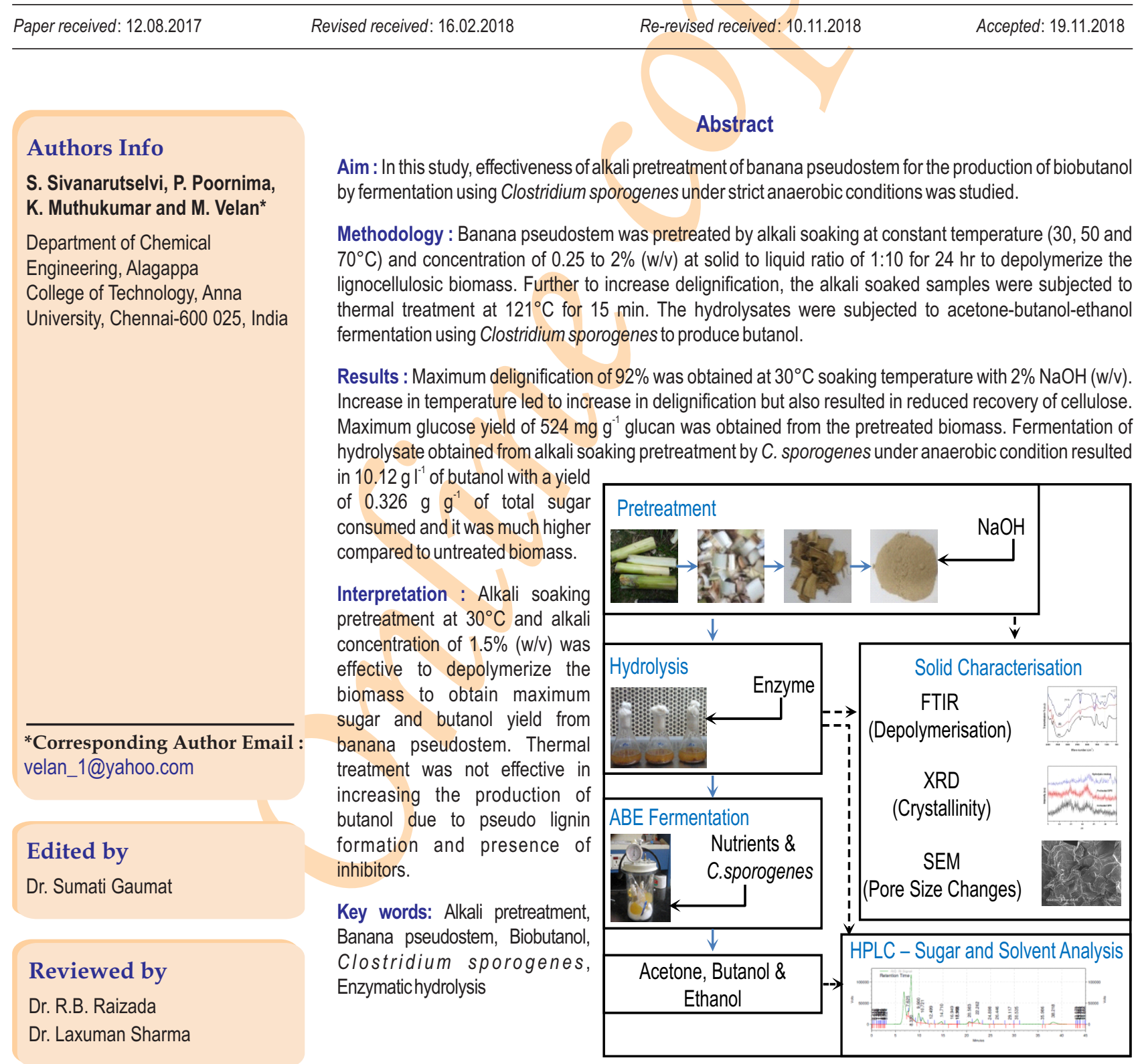

How to cite : Sivanarutselvi, S., P. Poornima, K. Muthukumar and M. Velan: Studies on effect of alkali pretreatment of banana pseudostem for fermentable sugar production for biobutanol production. J. Environ. Biol., 40, 393-399 (2019). 


\section{Introduction}

Biofuels are expected to play a major role in ensuring future energy security by reducing the fossil fuel dependency and mitigating climate change due to emission of greenhouse gases. Biobutanol is a next generation biofuel and considered superior to bioethanol due to higher energy density, lower Reid vapour pressure, easy blending with gasoline at any ratio and ease in transportation with the existing infrastructure (Bellido et al., 2014 Qureshi and Ezeji, 2008). It can be produced from renewable lignocellulosic wastes generated by agriculture and forestry (Diaz et al., 2013; Sellin et al., 2013). Banana pseudostem is a potential lignocellulosic biomass and has been evaluated for bioethanol production (Gabhane et al., 2014; Ingale et al., 2014). It has been reported as one of the most under-utilized biomass with great potential (Farooq et al., 2012; Padam et al., 2014). India is the largest producer of banana in the world and for each ton of banana harvest around three tons of banana pseudostem is generated (Souza et al., 2014). Lignocellulosic biomass mainly consists of cellulose, hemicellulose and lignin. In order to produce biofuel, lignocellulosic biomass based biorefinery involves four main steps namely, pretreatment, hydrolysis, fermentation and product separation. Pretreatment is a critical step and has significant impact on other steps of biorefinery process (Galbe and Zacchi, 2012). Due to complexity of lignocellulosic biomass matrix, usually a high energy input is required to maximize the sugar release during pretreatment (Yamakawa et al., 2018).

Pretreatment of lignocellulosic biomass is necessary to depolymerise the biomass by altering / removing lignin and to improve the accessibility of enzyme to cellulose for hydrolysis (Kumar et al., 2009). The methods employed in pretreatment include physical, physiochemical, chemical and biological techniques (Kumar and Sharma, 2017). Depolymerisation using alkaline treatment is one of the leading pretreatment methods for improving cellulose digestibility of lignocellulosic materials to degrade lignin from biomass and to recover cellulosic material (Balakrishnaraja et al., 2017; Mosier et al., 2005). In light of the above, the present study was carried out to investigate the effectiveness of alkali pretreatment of banana pseudostem for the production of biobutanol by anaerobic fermentation using Clostridium sporogenes.

\section{Materials and Methods}

Plant material: Samples of banana pseudostem were purchased from market in Chennai, (India), cut into $2 \mathrm{~cm}$ size pieces and washed to remove sand and dirt. It was dried in sunlight followed by heating in oven at $60^{\circ} \mathrm{C}$ till constant weight was obtained. The dried samples were ground to $<25$ mesh size and stored in air tight container for further use. Lyophilized Clostridium sporogenes (NCIM 2337) was procured from National Chemical Laboratory, Pune, India.

Pretreatment: In this study, two different pretreatments were carried out: Soaking banana pseudostem in $\mathrm{NaOH}$ solution ( 0.25 $2.0 \% \mathrm{w} / \mathrm{v}$ ) for $24 \mathrm{hr}$ at $30-70^{\circ} \mathrm{C}$ under shaking condition at a solid to liquid ratio of $1: 10$, followed by thermal treatment at $121^{\circ} \mathrm{C}$ and $15 \mathrm{psi}$ for $15 \mathrm{~min}$. After the treatment, solids were recovered by filtration, washed with water till neutral $\mathrm{pH}$ was observed and then dried at $60^{\circ} \mathrm{C}$ till constant weight was obtained. All the experiments were carried out in triplicate and the average values were reported and standard deviations were represented as error bars.

Enzymatic hydrolysis: Enzymatic hydrolysis of untreated and pretreated banana pseudostem was carried out at a solid loading of $1: 10$ in $50 \mathrm{mM}$ citrate buffer $\left(\mathrm{pH}^{4} .8\right)$ containing $50 \mathrm{FPU} \mathrm{g}{ }^{-1}$ biomass of cellulase and $350 \mathrm{U} \mathrm{g}^{-1}$ biomass of $\beta$-glucosidase. In addition, sodium azide $(0.02 \%)$ was added to prevent fungal growth. The contents were incubated in an orbital shaker at $50^{\circ} \mathrm{C}$ and $120 \mathrm{rpm}$ for $24 \mathrm{hr}$ (Selig et al., 2008) and at the end of the reaction, contents were centrifuged at $8000 \mathrm{rpm}$ for $15 \mathrm{~min}$. All the experiments were carried out in triplicate and the average values were reported and standard deviations were represented as error bars.

Anaerobic culture maintenance and fermentation: $C$. sporogenes spores were revived anaerobically inside an anaerobic culture jar system (HiMedia) in Reinforced Clostridia Agar and Reinforced Clostridia Medium at $37^{\circ} \mathrm{C}$ for $24 \mathrm{hr}$. Culture was maintained as spore suspension in sterile water at $4^{\circ} \mathrm{C}$. The inoculum was prepared in Clostridia medium containing $5 \mathrm{~g} \mathrm{l}^{-1}$ glucose, $5 \mathrm{gl}^{-1}$ yeast extract, $3 \mathrm{gl}^{-1}$ starch, $10 \mathrm{gl}^{-1}$ beef extract, $10 \mathrm{gl}^{-1}$ peptone, $5 \mathrm{gl}^{-1}$ sodium chloride, $3 \mathrm{gl}^{-1}$ sodium acetate, $0.5 \mathrm{gl}^{-1}$ agar and $0.5 \mathrm{gl}^{-1}$ cysteine hydrochloride. The $\mathrm{pH}$ of the medium was 7 . About $100 \mathrm{ml}$ of this medium was sterilized at $121^{\circ} \mathrm{C}$ and $15 \mathrm{psi}$, cooled to room temperature and inoculated with $C$. sporogenes culture. This was incubated for $24 \mathrm{hr}$ at $37 \pm 0.5^{\circ} \mathrm{C}$ inside an anaerobic culture jar until active growth was observed.

Fermentation was carried out in $150 \mathrm{ml}$ Erlenmeyer flasks in anaerobic culture jar using enzymatic hydrolysate as substrate. Hydrolysates containing higher sugar concentration from both the pretreatment methods were subjected to fermentation. Nutrients were added to the hydrolysate sample and was sterilized in an autoclave, cooled and inoculated with $10 \%$ (v/v) actively growing Clostridium sporogenes culture. Samples were collected at regular intervals ( $24 \mathrm{hr}$ ) to monitor the growth pattern and acetone-butanol-ethanol production. The yield is the ratio of amount of product obtained and total sugars utilized and productivity is the ratio of solvent production $\left(\mathrm{g} \mathrm{l}^{-1}\right)$ and fermentation time and was calculated as described by Qureshi etal. (2010).

Analytical methods: Cellulose, hemicellulose and lignin contents present in banana pseudostem were estimated by detergent extraction method (Goering and Van Soest, 1970). Fourier transform infrared spectroscopy (FTIR) with a detector at $4 \mathrm{~cm}^{-1}$ resolution and $25 \mathrm{scan}$ per sample was used to analyse the changes in functional groups. Scanning electron microscopy (SEM) was used to investigate the morphology of pretreated sample. The crystalline nature of banana pseudostem before and 
after pretreatment was analysed using GE X-ray diffraction system. The samples were scanned in the range of $2 \theta=5-35^{\circ}$ with a step size of $0.02^{\circ}$ and the crystallinity index (Crl) was determined by Eq. (1) (Segal et al., 1959).

$$
\% \mathrm{Crl}=\left\{\frac{\mathrm{I}_{002}-I_{\mathrm{am}}}{\mathrm{I}_{002}}\right\} \times 100
$$

where, $\mathrm{I}_{002}$ is the intensity of diffraction (002) plane at about $2 \theta=$ $22.5^{\circ}$ and $I_{a m}$ is the intensity of baseline at about $2 \theta=18.4^{\circ}$. The solid recovery after pretreatment was calculated by Eq. 2 (Gu et al., 2013).

$\%$ Solid recovery $=\{$ Dry pretreated solid $(\mathrm{g}) /$ Dry raw material $(\mathrm{g})\} \times$ 100

The $\%$ delignification and $\%$ cellulose recovery were calculated by Eq. 3 and 4 (Haykir et al., 2013):

$$
\begin{aligned}
& \% \text { Delignification }=\left(\left\{L_{\text {Uns }}-L_{P T S}\right) / L_{U n S}\right\} \times 100 \\
& \% \text { Cellulose recovery }=\left(C_{P T S} / C_{U n S}\right) \times 100
\end{aligned}
$$

where, $L_{\text {Uns }}$ is the lignin content in untreated sample and $L_{\text {PTS }}$ is the lignin content in pre-treated sample expressed in $\mathrm{g} \mathrm{g}^{-1}, \mathrm{C}_{\mathrm{PTS}}$ is the cellulose content of pre-treated sample and $C_{U n S}$ is the cellulose content of untreated sample expressed in $\mathrm{gg}^{-1}$. Monosaccharide sugars were analysed by high performance liquid chromatography (HPLC) equipped with refractive index detector (Agilent 1260 - Hi-Plex H column), using $5 \mathrm{mM}$ sulphuric acid as mobile phase at a flow rate of $0.6 \mathrm{ml} \mathrm{min}^{-1}$ at $65^{\circ} \mathrm{C}$ oven

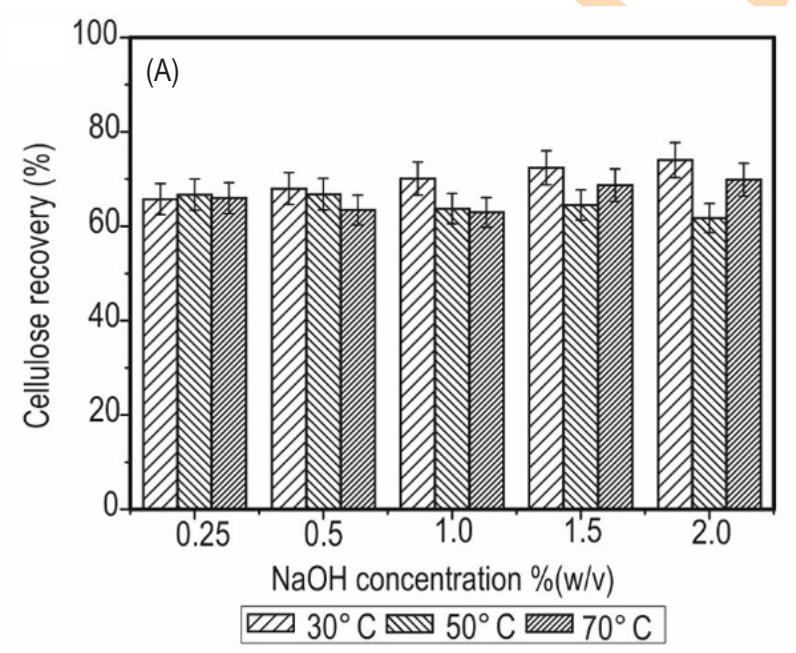

temperature and the fermentation products were analysed by HPLC with refractive index detector using HPLC grade water as mobile phase at a rate of $0.6 \mathrm{ml} \mathrm{min}^{-1}$ at $40^{\circ} \mathrm{C}$ oven temperature as recommended by the manufacturer and the analytical methods described in the literature (Kumar et al., 2014; Tsuey et al., 2006).

\section{Results and Discussion}

The amount of cellulose, hemicellulose and lignin present in untreated sample were $41.04,17.39$ and $10.51 \%$, respectively. This is in agreement with the results reported in literature Jayaprabha et al. (2011). Increase in alkali concentration and soaking temperature resulted in decreased solid recovery. As the concentration of alkali increased, cellulose recovery increased in alkali soaking method (Fig. 1). When the sample was further subjected to thermal treatment, cellulose recovery was reduced indicating higher dissolution of cellulose at higher alkali concentration. Cellulose recovery varied between 62.94 and $74.01 \%$ in alkali soaking pretreatment. With additional thermal pretreatment, the cellulose recovery varied between 53.13 and $86.27 \%$. Similar results were reported for low concentration alkali pretreatment of corncob (Sharma et al., 2017). It was also observed that the lignin was removed using lesser alkali concentration (up to $1 \% \mathrm{NaOH}$ ) and got precipitated during thermal treatment (Fig. 2). In case of higher alkali concentration, additional thermal treatment was effective in delignification. Maximum delignification of 91.27 and $91.52 \%$ was obtained at $30^{\circ} \mathrm{C}$ soaking temperature with 1.5 and $2.0 \%(\mathrm{w} / \mathrm{v}) \mathrm{NaOH}$, respectively, with additional thermal treatment. Under similar conditions, in the absence of thermal pretreatment, 57.33 and $77.57 \%$ delignification was observed.

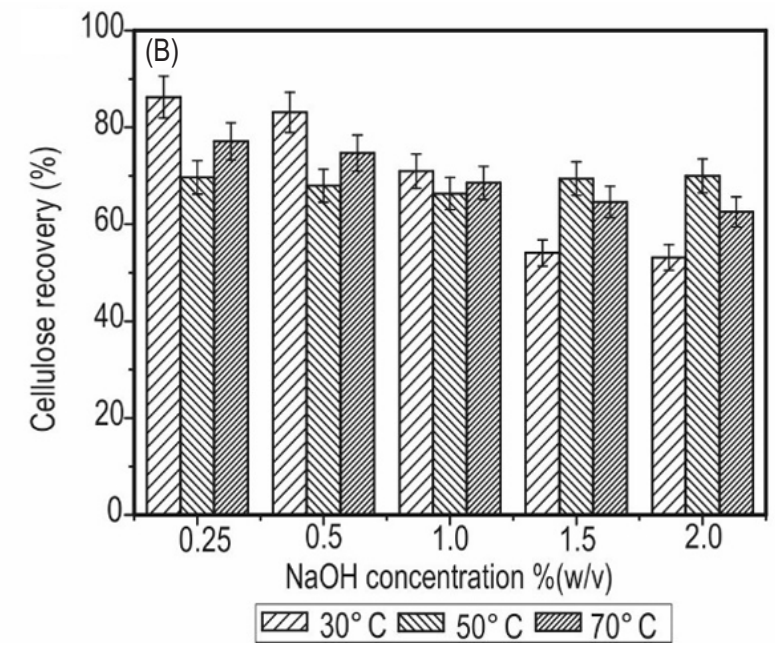

Fig. 1: Effect of $\mathrm{NaOH}$ concentration and soaking temperature on \% cellulose recovery (A) Alkali soaking pretreatment and (B) Alkali soaking + Thermal pretreatment. 

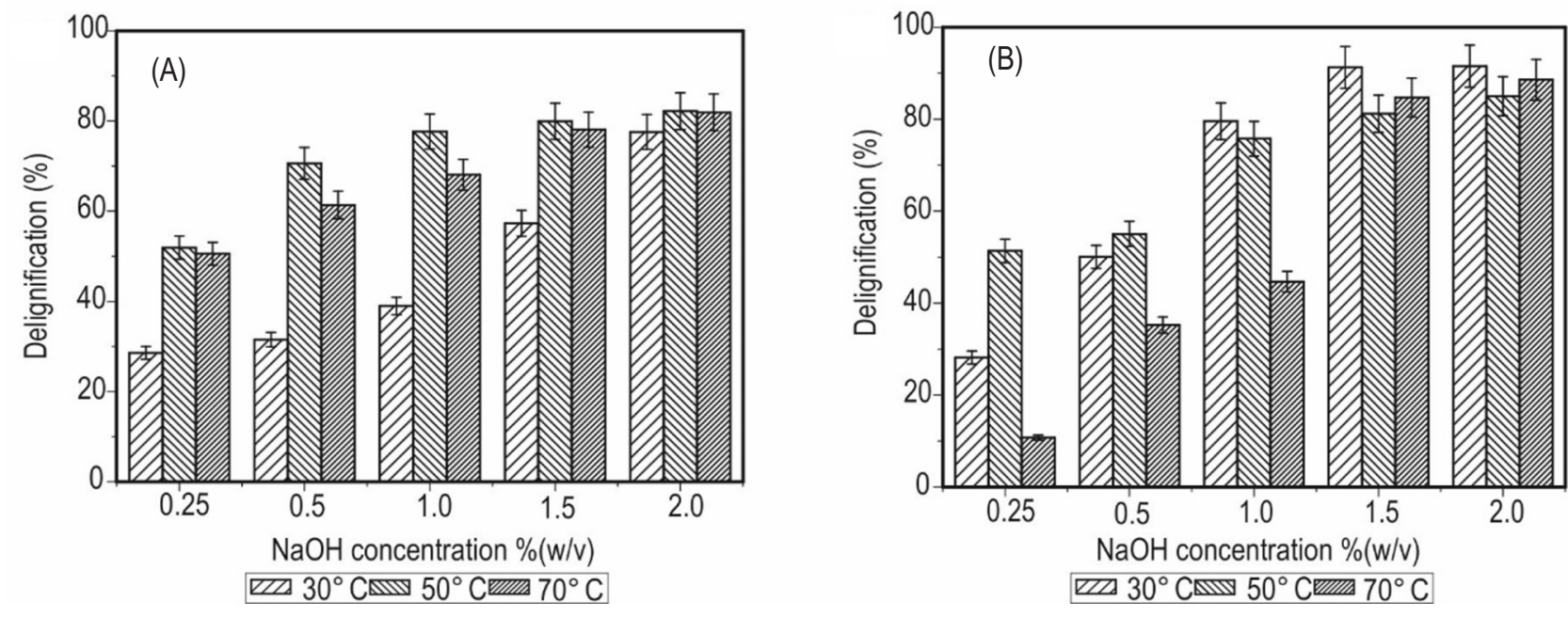

Fig. 2: Effect of $\mathrm{NaOH}$ concentration and soaking temperature on \%delignification (A) Alkali soaking pretreatment and (B) Alkali soaking + Thermal pretreatment.
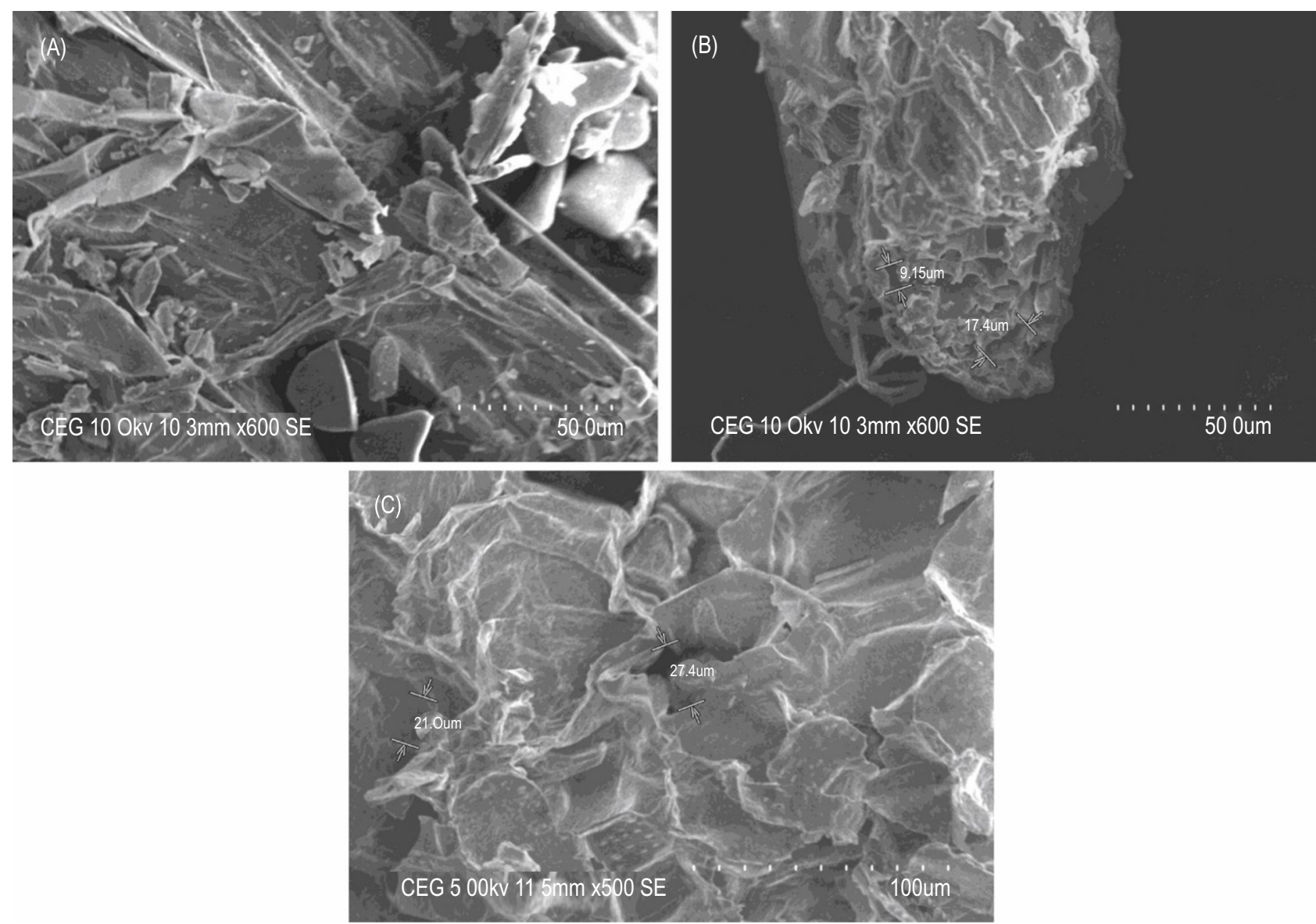

Fig. 3: SEM images of (A) untreated banana pseudostem, (B) pretreated banana pseudostem (conditions: 1:10 solid liquid ratio, $1.5 \%(\mathrm{w} / \mathrm{v}) \mathrm{NaOH}$ soaking at $30^{\circ} \mathrm{C}$ for $24 \mathrm{hr}$ ), (C) hydrolysis residue (conditions: $5 \mathrm{~g}$ pretreated biomass, $50 \mathrm{ml} \mathrm{mM}$ citrate buffer, $50^{\circ} \mathrm{C}, \mathrm{pH} 4.8$, cellulase $50 \mathrm{FPU} \mathrm{g}^{-1}$ biomass and $\beta$-glucosidase $350 \mathrm{U} \mathrm{g}^{-1}$ biomass). 


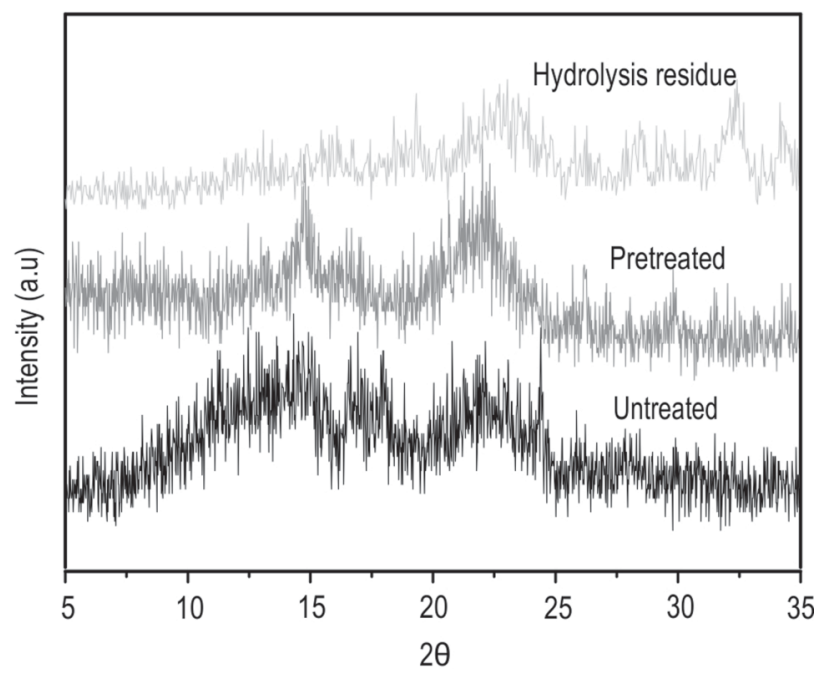

Fig. 4: XRD pattern of banana pseudostem: untreated, pretreated and hydrolysis residue (pretreatment condition: 1:10 solid liquid ratio, 1.5\% (w/v) $\mathrm{NaOH}$ soaking at $30^{\circ} \mathrm{C}$ for $24 \mathrm{hr}$ and hydrolysis condition: $5 \mathrm{~g}$ pretreated biomass, $50 \mathrm{ml} \mathrm{mM}$ citrate buffer, $50^{\circ} \mathrm{C}, \mathrm{pH} 4.8$, cellulase 50 FPU ${ }^{-1}$ biomass and $\beta$-glucosidase $350 \mathrm{U} \mathrm{g}^{-1}$ biomass).

Hence, it can be concluded that thermal pretreatment had significantly improved delignification.

It was observed that the pretreatment had induced significant physical changes in the biomass. Smooth and continuous surface was observed from the SEM images of untreated sample (Fig. 3A). Smaller porosities and undamaged fibrous organization were found in the smoother walls of untreated banana pseudostem sample (Bilba et al., 2007; Shimizu et al., 2018). Damaged and relatively less smooth surface with pores were observed in thermally treated sample. SEM image of hydrolysis residue exhibited pores of higher sizes and completely damaged cell wall, confirming the release of sugars (Fig. 3C).

X-ray diffraction analysis of untreated, pretreated and hydrolysed banana pseudostem was performed and is shown in Fig. 4. Crystallinity index ( $\mathrm{Crl})$ is an indication of the extent of material destruction. $\mathrm{Crl}$ of untreated sample was found to be $34 \%$ and it was closer to the value of $39 \%$ reported earlier by Guimarães et al. (2009). The Crl of pretreated sample increased to $57 \%$, indicating partial hydrolysis of hemicellulose and removal of lignin caused by alkali pretreatment. On further enzymatic hydrolysis, the amorphous cellulose was easily digested by enzyme mixture leaving behind the crystalline cellulose resulting in $55 \% \mathrm{Crl}$. There was no direct relationship between digestibility and $\mathrm{Crl}$ value, but there was a close relationship with hemicellulose and lignin removal (Yu et al., 2013a).

Fourier Transform Infrared Spectroscopy was used to investigate the changes in cellulose structures during alkali

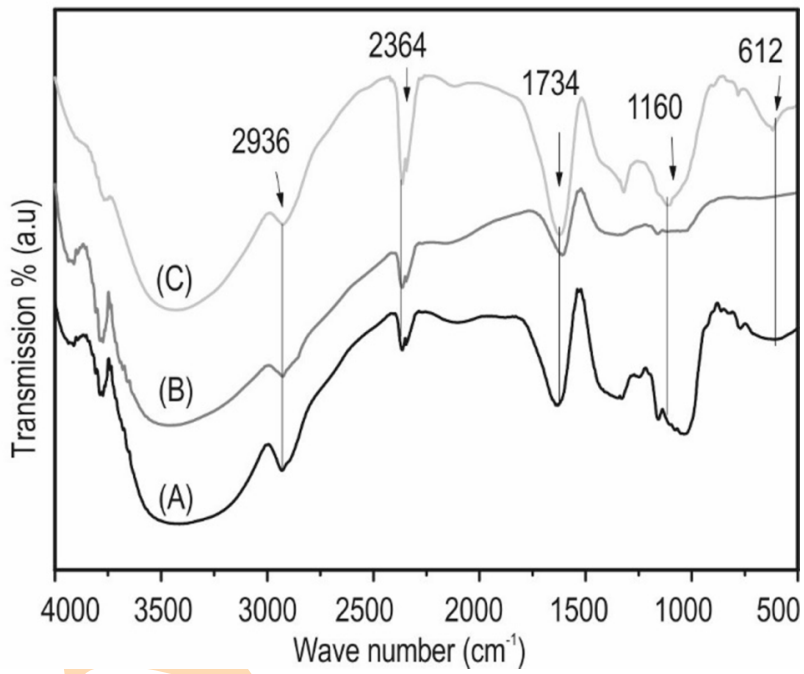

Fig. 5: FTIR spectra of banana pseudostem: (A) untreated, (B) pretreated and $(\mathrm{C})$ hydrolysis residue (pretreatment condition: 1:10 solid liquid ratio, $1.5 \%$ (w/v) $\mathrm{NaOH}$ soaking at $30^{\circ} \mathrm{C}$ for $24 \mathrm{hr}$ and hydrolysis condition: $5 \mathrm{~g}$ pretreated biomass, $50 \mathrm{ml} \mathrm{mM}$ citrate buffer, $50^{\circ} \mathrm{C}, \mathrm{pH} 4.8$, cellulase $50 \mathrm{FPU} \mathrm{g}^{-1}$ biomass and $\beta$-glucosidase $350 \mathrm{U} \mathrm{g}^{-1}$ biomass).

pretreatment and is shown in Fig. 5. The prominent bands observed at $1000-1200 \mathrm{~cm}^{-1}$ indicated the structural features of cellulose and hemicellulose, and the enhanced absorption peaks in this region indicated the elevated levels of cellulose, was similar to the results reported by Zhao et al. (2010). The peak at $1160 \mathrm{~cm}^{-1}$ indicated modification in cellulose. The absorption at $2910 \mathrm{~cm}^{-1}$ represents the stretching of $-\mathrm{CH}_{3}$ and $-\mathrm{CH}_{2}$ indicating the changes due to pretreatment (Binod et al., 2009).

Enzymatic hydrolysis was used to convert cellulose and hemicellulose into hexose (glucose) and pentose sugars (xylose and arabinose). The pretreated and untreated banana pseudostem samples were hydrolysed using cellulase (50 FPU g ${ }^{1}$ biomass) supplemented with $\beta$-glucosidase ( $350 \mathrm{U} \mathrm{g}^{-1}$ biomass) in order to obtain maximum glucose yield. Fig. 6 shows the effect of $\mathrm{NaOH}$ concentration and soaking temperature on glucose yield from pretreated sample by alkali soaking (BPSASEH) and alkali soaking, followed by thermal treatment (BPSASTEH) and untreated sample (BPSEH). Glucose yield decreased with an increase in soaking temperature. Maximum glucose yield of 524 $\mathrm{mg} \mathrm{g}^{-1}$ glucan was obtained from the sample treated at $30^{\circ} \mathrm{C}$ with $1.5 \% \mathrm{NaOH}$. In case of sample treated under similar conditions with additional thermal treatment resulted in lesser yield of $431 \mathrm{mg} \mathrm{g}^{-1}$ glucan, inspite of higher delignification $(91.27 \%)$, this might be due to the condensation of lignin pseudo molecule hindering hydrolysis as reported by Yu et al. (2013b). Distribution of lignin and its modification is important for the enzymatic digestibility of lignocellulosic biomass rather than its removal (Taherzadeh and Karimi, 2008; Yang and Wyman, 2004). In this study, alkali pretreatment $\left(30^{\circ} \mathrm{C}\right.$ with 

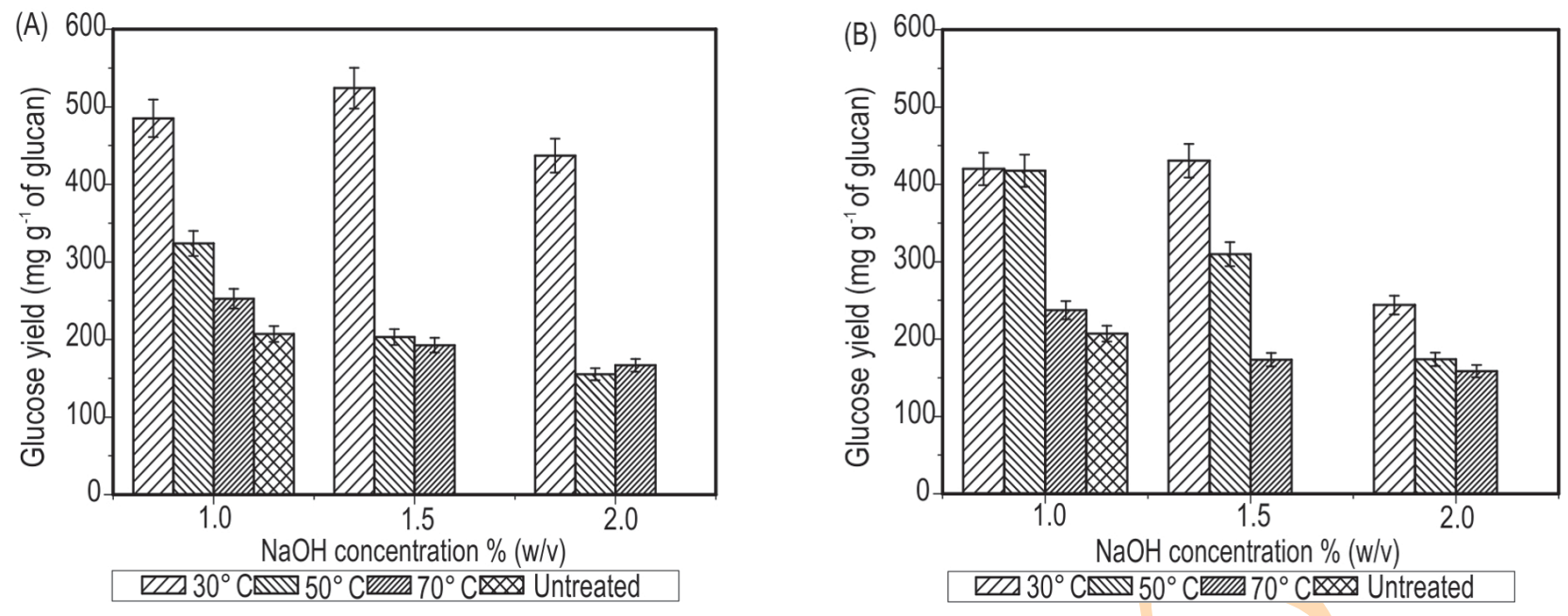

Fig. 6: . Effect of $\mathrm{NaOH}$ concentration of glucose yield from banana pseudostem (conditions: $5 \mathrm{~g}$ untreated / pretreated biomass, $50 \mathrm{ml} \mathrm{mM}$ citrate buffer, $50^{\circ} \mathrm{C}, \mathrm{pH} 4.8$, cellulase $50 \mathrm{FPU} \mathrm{g}^{-1}$ biomass and $\beta$-glucosidase $350 \mathrm{U} \mathrm{g}^{-1}$ biomass) (A) Soaking pretreatment and (B) Soaking + Thermal pretreatment.

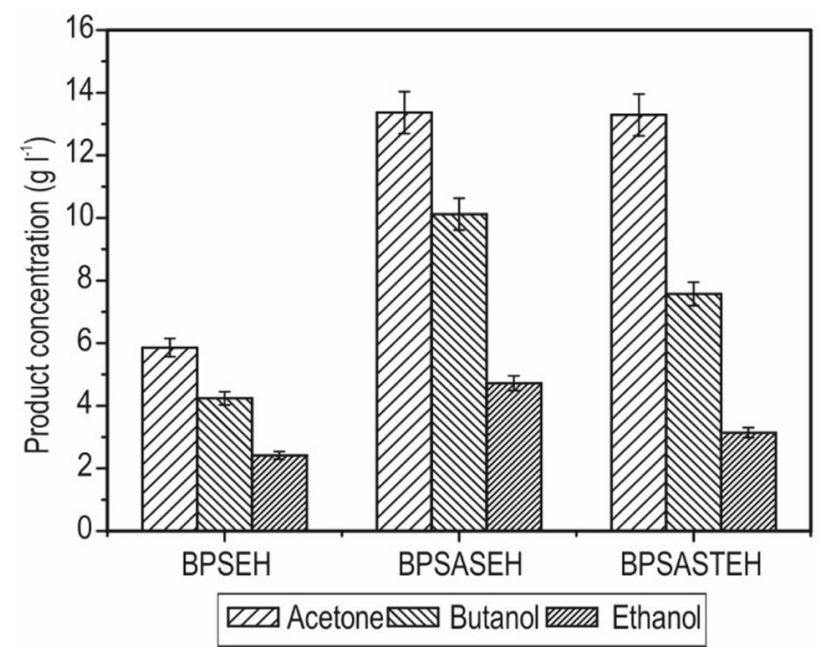

Fig. 7: Comparative analysis of fermentation products by fermentation of BPSEH, BPSASEH, BPSASTEH using Clostridium sporogenes at $37^{\circ} \mathrm{C}$, $\mathrm{pH} 7$ and $10 \%$ inoculum.

$1.5 \% \mathrm{NaOH})$ improved the glucose yield by 2.53 times compared to untreated banana pseudostem.

Samples with higher sugar concentration obtained from hydrolysis process were subjected to fermentation using $C$. sporogenes under strict anaerobic conditions. Fermentation profile of product formation and sugar was studied for seven days. The concentration of ethanol and butanol were found to be constant after $72 \mathrm{hr}$ of fermentation and the concentration of acetone was further found to be increased. Hence, all the results were compared at the end of $72 \mathrm{hr}$ of fermentation and the results are presented in Fig. 7. Initial glucose concentration of fermentation medium after the addition of nutrients and inoculum were 12.26, 29.23 and $24.9 \mathrm{~g} \mathrm{I}^{-1}$ for untreated banana pseudostem (BPSEH), sample pretreated by alkali soaking (BPSASEH) and alkali soaking followed by thermal pretreatment (BPSASTEH), respectively. Xylose present in BPSEH, BPSASEH and BPSASTEH were 5.16, 3.12 and $2.72 \mathrm{gl}^{-1}$. Anaerobic fermentation of BPSEH using C.sporogenes resulted in 5.87, 4.24 and $2.42 \mathrm{gl}^{-1}$ of acetone, butanol and ethanol, respectively, with butanol yield of $0.276 \mathrm{~g} \mathrm{~g}^{-1}$ and total sugar consumption was $15.36 \mathrm{gl}^{-1}$ including 3.1 $\mathrm{g} \mathrm{I}^{-1}$ of xylose. Fermentation of BPSASEH produced 13.37, 10.12 and $4.72 \mathrm{~g} \mathrm{I}^{-1}$ of acetone, butanol and ethanol, respectively, with butanol yield of $0.326 \mathrm{~g} \mathrm{~g}^{-1}$ by consuming $31.04 \mathrm{~g} \mathrm{l}^{-1}$ of total sugar including $1.81 \mathrm{~g} \mathrm{I}^{-1}$ xylose. However, fermentation of BPSASTEH produced 13.29, 7.57 and $3.1 \mathrm{~g} \mathrm{I}^{-1}$ of acetone, butanol and ethanol, respectively, with butanol yield of $0.288 \mathrm{~g} \mathrm{~g}^{-1}$ by consuming $26.26 \mathrm{gl}^{-1}$ of total sugar of which $1.36 \mathrm{~g} \mathrm{l}^{-1}$ was xylose. The lesser yield of butanol from hydrolysate indicated the presence of inhibitors during pretreatment.

Hence, it can be concluded that the structural modification of lignin is sufficient to maximise the sugar and butanol yield than its removal. The evaluated pretreatment method for banana pseudostem requires less energy and is suitable for tropical countries like India. Banana pseudostem can be a potential feedstock for the production of biobutanol.

\section{Acknowledgment}

This work was funded by Department of Science and Technology, New Delhi, India, under Women Scientist scheme (DST - WOS A). The first author gratefully acknowledges the DST, India for providing the financial support. 


\section{References}

Balakrishnaraja, R., S. Balasubramanian, P. Aravindan, A. Arulraj, K. Selvapriya, S. Geethadevi and N. Rao: Optimization of ethanol production using pretreated corn cob and sugarcane bagasse hydrolysate by Candida parapsilosis strain BKR1. J. Environ. Biol., 38, 1357-1363 (2017).

Bellido, C., M. Loureiro Pinto, M. Coca, G. Gonzalez-Benito and M. T. Garcia-Cubero: Acetone-butanol-ethanol (ABE) production by Clostridium beijerinckii from wheat straw hydrolysates: Efficient use of penta and hexa carbohydrates. Bioresour. Technol., 167, 198-205 (2014).

Bilba, K., M. A. Arsene and A. Ouensanga: Study of banana and coconut fibers. Botanical composition, thermal degradation and textura observations. Bioresour. Technol., 98, 58-68 (2007).

Binod, P., R. Sindhu, R.R. Singhania, S. Vikram, L. Devi, S Nagalakshmi, N. Kurien, R.K. Sukumaran and A. Pandey: Bioethanol production from rice straw: An overview. Bioresour. Technol., 101, 4767-4774 (2009).

Diaz, A., J. Le Toullec, A. Blandino, I. De Ory and I. Caro: Pretreatment of rice hulls with alkaline peroxide to enhance enzyme hydrolysis for ethanol production. Chem. Eng. Trans., 32, 949-954 (2013).

Farooq, S., S. Zafar, A. Q. Rather and T. Ali: Characterization and evaluation of banana waste (Musa paradisica L.) as a raw material for paper production. Int. J. Environ. Bioene., 4, 1-7 (2012).

Gabhane, J., S. P. M. Prince William, A. Gadhe, R. Rath, A. N. Vaidya and $S$. Wate: Pretreatment of banana agricultural waste for bio-ethanol production: Individual and interactive effects of acid and alkali pretreatments with autoclaving, microwave heating and ultrasonication. Waste Manag., 34, 498-503 (2014).

Galbe, M. and G. Zacchi: Pretreatment: The key to efficient utilization of lignocellulosic materials. Biomass and Bioenergy, 46, 70-78 (2012).

Goering, H. K. and P. J. Van Soest: Forage fiber analyses (Apparatus reagent, procedures and some applications): Agriculture Handbook No. 379, Agricultural Research Service, United States Department of Agriculture, Washington DC, USA(1970).

Gu, F., W. Wang, L. Jing and Y. Jin: Effects of green liquor pretreatment on the chemical composition and enzymatic digestibility of ricestraw. Bioresour. Technol., 149, 375-382 (2013).

Guimarães, J.L., E. Frollini, C.G. da Silva, F. Wypych and K.G. Satyanarayana: Characterization of banana, sugarcane bagasse and sponge gourd fibers of Brazil. Ind. Crops Prod., 30, 407-415 (2009).

Haykir, N. I., E. Bahcegul, N. Bicak and U. Bakir: Pretreatment of cotton stalk with ionic liquids including 2-hydroxy ethyl ammonium formate to enhance biomass digestibility. Ind. Crops Prod., 41, 430-436 (2013).

Ingale, S., S.J. Joshi and A. Gupte: Production of bioethanol using agricultural waste: Banana pseudo stem. Brazilian J. Microbiol., 45, 885-892 (2014)

Jayaprabha, J.S., M. Brahmakumar and V.B. Manilal: Banana pseudostem characterization and its fiber property evaluation on physical and bioextraction. J. Nat. Fibers, 8, 149-160 (2011).

Kumar, A.K. and S. Sharma: Recent updates on different methods of pretreatment of lignocellulosic feedstocks: A review. Bioresour. Bioprocess., 4, 7 (2017)

Kumar, M., S. Saini and K. Gayen: Acetone-butanol-ethanol fermentation analysis using only high performance liquid chromatography. Anal. Methods, 6, 774-781 (2014).

Kumar, P., D. M. Barrett, M. J. Delwiche and P. Stroeve: Methods for pretreatment of lignocellulosic biomass for efficient hydrolysis and biofuel production. Ind. Eng. Chem. Res., 48, 3713-3729 (2009).

Mosier, N., C. Wyman, B. Dale, R. Elander, Y. Y. Lee, M. Holtzapple and M. Ladisch: Features of promising technologies for pretreatment of lignocellulosic biomass. Bioresour. Technol., 96,673-686 (2005).

Padam, B. S., H. S. Tin, F. Y. Chye and M. I. Abdullah: Banana byproducts: An under-utilized renewable food biomass with great potential. J. Food Sci. Technol., 51, 3527-3545 (2014).

Qureshi, N. and T. C. Ezeji: Butanol, "a superior biofuel" production from agricultural residues (renewable biomass): Recent progress in technology. Biofuels, Bioprod. Biorefining, 2, 319-330 (2008).

Qureshi, N., B. C. Saha, B. Dien, R. E. Hector and M. A. Cotta: Production of butanol (a biofuel) from agricultural residues: Part I - Use of barley straw hydrolysate. Biomass and Bioenergy, 34, 559-565 (2010).

Segal, L., J. J. Creely, A. E. Martin and C. M. Conrad: An empirical method for estimating the degree of crystallinity of native cellulose using the X-ray diffractometer. Text. Res. J., 29, 786-794 (1959).

Selig, M., N. Weiss and Y. Ji: Enzymatic Saccharification of Lignocellulosic Biomass: Laboratory Analytical Procedure (LAP) NREL/TP-510-42629. Golden, CO, National Renewable Energy Laboratory (2008)

Sellin, N., B. G. De Oliveira, C. Marangoni, O. Souza, A. P. N. De Oliveira and T. M. Novais De Oliveira: Use of banana culture waste to produce briquettes. Chem. Eng. Trans., 32, 349-354 (2013).

Sharma, A., V. Nain, R. Tiwari, S. Singh, A. Adak, P.K.S. Nain and L. Nain: Simultaneous saccharification and fermentation of alkali-pretreated corncob under optimized conditions using cold-tolerant indigenous holocellulase. Korean J. Chem. Eng., 34, 773-780 (2017).

Shimizu,F.L., P.Q. Monteiro, P.H.C. Ghiraldi, R. B. Melati, F.C. Pagnocca, W. de Souza, C. Sant'Anna and M. Brienzo: Acid, alkali and peroxide pretreatments increase the cellulose accessibilityand glucose yield of banana pseudostem. Ind. Crops Prod., 115, 62-68 (2018).

Souza, E.L., G.F. Liebl, C. Marangoni, N. Sellin and S. Millena: Bioethanol from fresh and dried banana plant pseudostem. Chem. Eng. Trans., 38, 271-276 (2014).

Taherzadeh, M. J. and K. Karimi: Pretreatment of lignocellulosic wastes to improve ethanol and biogas production: A review. Int. J. Mol. Sci., 9, 1621-1651 (2008).

Tsuey, L. S., A. Bin Ariff, R. Mohamad and R. A. Rahim: Improvements of GC and HPLC analyses in solvent (acetone-butanol-ethanol) fermentation by Clostridium saccharobutylicum using a mixture of starch and glycerol as carbon source. Biotechnol. Bioprocess Eng., 11, 293-298 (2006).

Yamakawa, C.K., F. Qin and S.I. Mussatto:Advances and opportunities in biomass conversion technologies and biorefineries for the development of a bio-based economy. Biomass and Bioenergy, $119,54-60(2018)$

Yang, B. and C. E. Wyman: Effect of xylan and lignin removal by batch and flowthrough pretreatment on the enzymatic digestibility of corn stover cellulose. Biotechnol. Bioeng., 86, 88-95 (2004).

Yu, Q., X. Zhuang, S. Lv, M. He, Y. Zhang, Z. Yuan, W. Qi, Q. Wang, W. Wang and $X$. Tan: Liquid hot water pretreatment of sugarcane bagasse and its comparison with chemical pretreatment methods for the sugar recovery and structural changes. Bioresour. Technol., 129, 592-598 (2013a)

Yu, Q., X. Zhuang, Z. Yuan, W. Qi, W. Wang, Q. Wang and X. Tan: Pretreatment of sugarcane bagasse with liquid hot water and aqueous ammonia. Bioresour. Technol., 144, 210-215(2013b).

Zhao, X., E. van der Heide, T. Zhang and D. Liu: Delignification of sugarcane bagasse with alkali and peracetic acid and characterization of the pulp. BioResources, 5, 1565-1580 (2010). 